\title{
MONUMENTA ICONOGRÁFICA AMERICANA: \\ LA IMAGEN DE AMÉRICA EN LAS ARTES EUROPEAS E IBEROAMERICANAS ${ }^{1}$
}

\author{
YOLANDA FERNÁNDEZ MUÑOZ \\ Universidad de Extremadura \\ ALICIA DÍAZ MAYORDOMO \\ Universidad de Extremadura
}

\section{RESUMEN}

El grupo de investigación «Extremadura y América» de la Universidad de Extremadura, presenta el proyecto Monumenta Iconográfica Américana: La imagen de América en las artes europeas e iberoamericanas, para crear un gran banco de imágenes sobre la iconografía de la imagen de América en los tiempos de la modernidad y la contemporaneidad, mediante el trabajo de búsqueda, recopilación y análisis de diferentes acervos documentales y bibliográficos nacionales e internacionales. El repertorio iconográfico ocupará desde las cartas ilustradas de Colón impresas en 1493 hasta la imagen del continente americano que se ha dado en el arte, el cine, la prensa gráfica y en los mass media del siglo XX, haciendo especial hincapié en la imagen de la mujer en todos los apartados.

Palabras clave: Imagen, iconografía, América, Europa, mujer.

1 Concedido en el marco de las Ayudas destinadas a la realización de proyectos de investigación en los centros públicos de I+D+I de la comunidad autónoma de Extremadura en la convocatoria 2020 (IB20133). Página en construcción del proyecto de investigación: FERNÁNDEZ MUÑOZ, Y., La imagen de América, disponible en: https://acortesg01.wixsite.com/laimagendeamerica 


\section{ABSTRACT}

The research group «Extremadura and America» of the University of Extremadura, presents the project American Iconographic Monument: The image of America in European and Latin American arts, to create a large image bank on the iconography of the image of America in modern and contemporary times, through the work of searching, collecting and analyzing different national and international documentary and bibliographic archives. The iconographic repertoire will occupy from the illustrated letters of Columbus printed in 1493 to the image of the American continent that has been given in the art, the cinema, the graphical press and in the mass media of the XX century, making special emphasis in the image of the woman in all the sections.

Keywords: Image, iconography, America, woman, Europe.

\section{EL GRUPO DE INVESTIGACIÓN EXTREM@MÉRICA}

Sobre la base de los estudios, los proyectos de investigación y las líneas de trabajo desarrollados por sus diferentes miembros, tanto de forma individual, como colectiva, el grupo de investigación «Extremadura y América», con el acrónimo «Extrem@mérica»", de la Universidad de Extremadura, comienza esta nueva andadura en el año 2018 bajo la dirección del Dr. Francisco Javier Pizarro Gómez, catedrático en Arte Iberoamericano.

Desde su conformación independiente como grupo americanista, trata de consolidarse como un equipo de investigación especializado en temas históricos, histórico-artísticos, jurídicos, educativos y culturales, extremeños e iberoamericanos. No en vano, está compuesto por investigadores de la Universidad de Extremadura de diferentes ramas de conocimiento, pero vinculados de una forma u otra con el ámbito americano ${ }^{3}$. El grupo Extrem@mérica centra sus objetivos científicos en el análisis del patrimonio histórico y cultural de Extremadura y América, así como en las relaciones que entre estos puedan establecerse a través de la presencia de escritores, pensadores, juristas, artistas y

2 Página en construcción del Grupo de Investigación Extremadura y América (Extrem@mérica). Disponible en: https://www.eweb.unex.es/eweb/extremamerica/

3 Entre sus miembros se encuentran, además del IP, los siguientes investigadores de la UEx: Dr. Florencio J. García Mogollón (catedrático en $\mathrm{H}^{\mathrm{a}}$ del Arte), Dra. Rosa Perales Piqueres (prof. titular de $\mathrm{H}^{\mathrm{a}}$ del Arte), Dr. Sixto Sánchez-Lauro Pérez (prof. titular de Derecho), Dra. Yolanda Fernández Muñoz, (prof. titular de $\mathrm{H}^{\mathrm{a}}$ del Arte), Dr. Modesto Rangel Mayoral (prof. titular en Educación), M ${ }^{\mathrm{a}}$ Teresa Rodríguez Prieto (directora del Museo de Bellas Artes de Badajoz), y el personal con contrato predoctoral: Alicia Díaz Mayordomo y Francisco J. Cambero Santano. 
promotores extremeños en Iberoamérica, y al trasplante de recursos culturales, modelos y tipologías de origen extremeño en los territorios del Nuevo Mundo. Para alcanzar estos fines son fundamentales los vínculos que mantiene con universidades, instituciones e investigadores, europeos e iberoamericanos, como la Universidad Popular Autónoma del Estado de Puebla (México), la Benemérita Universidad Autónoma de Puebla (México) o la Universidad Nacional Autónoma de México, entre otras. También es reseñable la colaboración con otros grupos americanistas nacionales, como «Andalucía-América: Patrimonio Cultural y Relaciones Artísticas» de la Universidad de Granada, o el grupo «Universo Barroco Iberoamericano» de la Universidad Pablo de Olavide de Sevilla, entre otros.

La investigación de los componentes del grupo en los temas iberoamericanos se plantea como una larga trayectoria, siendo iniciada por los miembros más experimentados en las décadas de los ochenta y noventa del siglo pasado, y por los miembros más noveles ya en el siglo XXI, y versan fundamentalmente sobre el patrimonio extremeño moderno y contemporáneo, las relaciones artísticas entre Extremadura y América, la arquitectura y el urbanismo virreinales, la iconografia, la emblemática y el arte efímero de los siglos XVI al XVIII. Algunas de las publicaciones más recientes son: Puebla Monumental. Patrimonio de la Humanidad (2015), 485 Aniversario de la Fundación de Puebla (2017) o Los conventos del siglo XVI de Puebla y Morelos (2018), realizadas por un equipo hispano-mexicano de historiadores del arte y arquitectos, o la edición facsimilar comentada del Libro primero de la Gobernación Espiritual de las Indias de Juan de Ovando (2020).

Tampoco podemos olvidar las jornadas, seminarios y cursos de verano, como las Jornadas de Cultura Novohispana, organizadas por el grupo y el Cuerpo Académico de Cultura Novohispana, que se celebran de forma anual, alternando las sedes en Extremadura y Puebla (México), cuyo objetivo fundamental es poner en común temas relacionados con la cultura, la sociedad, la historia o el pensamiento novohispano. También es reseñable el IV Simposio Internacional de Jóvenes Investigadores del Barroco Iberoamericano «Las orillas del Barroco», que se celebró en abril de 2019 en Extremadura y tuvimos la oportunidad de coordinar, cuyo objetivo principal era establecer las conexiones existentes entre los movimientos culturales y artísticos del Barroco Iberoamericano, a ambas orillas del Atlántico, tanto en la Edad Moderna como en la continuidad temporal que pervive en nuestros días. Finalmente, las Jornadas Internacionales de Pintura Mexicana del siglo XIX, organizadas por el grupo en 2018, buscaban mostrar las diferentes visiones, miradas y reflejos de la 
pintura de ese momento en España y México, y, como resultado de las mismas, surge la idea de realizar el proyecto que aquí presentamos.

Sin embargo, será en los años noventa cuando el Dr. Pizarro publique sus primeras aportaciones sobre el mundo de la iconografía y la cultura simbólica europeas, así como al análisis de la imagen de América. Entre sus publicaciones destacan: «La iconografía del Nuevo Mundo y su repercusión en las artes españolas y portuguesas» (1989), «La imagen de Las Antillas. Entre el mito y el tópico» (1997) o «Mitos y monstruos en el imaginario americano como laberintos de identidad» (1999), entre otras ${ }^{4}$. También imparte algunos cursos y comunicaciones relacionados con el mismo tema, como La imagen de América y su proyección artística (1995), La imagen de América. Entre el mito y el tópico (1998), Mitos y Monstruos en la imagen de América (1998) o La retórica de la imagen en la visión europea de América (2002). A todos estos títulos debemos sumar las aportaciones posteriores de otros miembros del grupo que participan en el proyecto, como: «La imagen plástica de la llegada de occidente a Nueva España entre 1517 y 1519 y del encuentro entre dos mundos» (2018), «La imagen de México en las Exposiciones Universales en la segunda mitad del siglo XIX» (2019) o «Pintura ilusionista y mensaje iconográfico» (2020) de la Dra. Fernández Muñoz ${ }^{5}$; el «Diccionario de personajes ilustres de Segovia. Rubén Landa Vaz» (2018) del Dr. Rangel Mayoral6; «El caballo de Pizarro: Representaciones artísticas y realidad histórica» (2018) y «La conquista de México a través de sus protagonistas: análisis de la escultura pública del XIX entre dos

4 PIZARRO GÓMEZ, F. J., «La iconografía del Nuevo Mundo y su repercusión en las artes españolas y portuguesas», en Actas del V Simposio Hispano-Portugués de Historia del Arte. Relaciones artísticas entre la Península Ibérica y América, Valladolid, Universidad de Valladolid, 1989, pp. 215226; «La memoria histórica de la arquitectura precolombina en la imagen literaria y artística de las crónicas», Boletín del INAH, 44, 1996, pp. 3-12; «La imagen de Las Antillas. Entre el mito y el tópico», en Actas del I Congreso Internacional «Nueva España y Las Antillas», Castellón, Universidad Jaime I/CIAL, 1997; «Mitos y monstruos del imaginario americano como laberinto de la identidad», en Laberintos e nós: Imagen ibérica em terras da América; São Paulo (Brasil), UNSP, 1999, pp. 21-38; «Extremadura en el viaje iconográfico del Cristo de la Encina entre Europa y América», Quiroga, 12, 2017, pp. 73-82.

5 FERNÁNDEZ MUÑOZ, Y., «La imagen plástica de la llegada de occidente a Nueva España entre 1517 y 1519 y del encuentro entre dos mundos», Jornada Encuentro 500 años de Historia Compartida, México, ANHGM, 2018; «500 años de imágenes de la llegada a América y sus protagonistas», Jornada sobre relaciones histórico-artísticas de España y América, Oaxaca (México), 2018; «La imagen de México en las Exposiciones Universales en la segunda mitad del siglo XIX», en Simposio Internacional Artes plásticas y cultura visual del siglo XIX en México. Conexiones entre España y América, Puebla, BUAP, Colección Lafuente, 2019; FERNÁNDEZ MUÑOZ, Y. y PIZARRO GÓMEZ, F. J., «Pintura ilusionista y mensaje iconográfico. Entre la ilusión óptica, el efectismo cromático y el discurso edificante. Ejemplos extremeños del siglo XVIII», Pintura ilusionista entre Europa y América, Sevilla, Universidad Pablo de Olavide/Enredars Publicaciones, 2020, pp.145-158.

6 RANGEL MAYORAL, M., «Diccionario de personajes ilustres de Segovia. Rubén Landa Vaz», en Diccionario de Historia y Arte de San Quirce, Segovia, 2018. 
Mundos» (2019) de Francisco Javier Cambero Santano ${ }^{7}$; «Obras de la escuela quiteña en Extremadura» (2017), «Efigies del poder en el siglo XIX. Las galerías de retratos de gobernantes de México y su proyección en las artes plásticas: de Hernán Cortés a Benito Juárez» (2019) o «Arquitectura, artificio y memoria simbólica: la consagración del nuevo convento de San Francisco en Lima (1673) y el obispo Mollinedo», de Alicia Díaz Mayordomo ${ }^{8}$.

\section{MONUMENTA ICONOGRÁFICA AMERICANA, UNA PROPUESTA DE FUTURO}

En los últimos años, el diseño, creación y proyección de recursos digitales para la trasferencia del legado patrimonial, han otorgado un valor añadido a las líneas, publicaciones y trabajos científicos desarrollados por los grupos de investigación en el ámbito de las Ciencias Sociales y las Humanidades, y se ha convertido en uno de los objetivos específicos de las instituciones y los organismos culturales.

Estamos ante un paradigma de cambio que, sin embargo, se presenta como un desafío para la comunidad científica universitaria, un colectivo que plantea numerosos interrogantes sobre cómo identificar y formular medidas y herramientas tecnológicas de difusión eficaces. Indudablemente, esta barrera se ha pasado de forma muy eficiente en museos, fundaciones, archivos, etcétera., a distintos niveles territoriales, por medio de actividades como la digitalización de libros y documentos, el compendio de artículos o la visualización universal de obras maestras de la Historia del Arte, haciendo de la Cultura el eje de desarrollo transversal.

7 CAMBERO SANTANO, F.J., «La conquista de México a través de sus protagonistas: análisis de la escultura pública del XIX entre dos Mundos», en Simposio Internacional Artes plásticas y cultura visual del siglo XIX en México. Conexiones entre España y América, Puebla, BUAP, Colección Lafuente, 2019; CAMBERO SANTANO, F.J. y MARTÍN CUERVO, M., «El caballo de Pizarro: representaciones artísticas y realidad histórica», en XLIV Coloquios Históricos de Extremadura: dedicados a la Ilustración en Extremadura como movimiento filosófico, artístico, científico y político, Trujillo, Asociación Cultural Coloquios Históricos de Extremadura, 2018, pp. 121-145.

8 DÍAZ MAYORDOMO, A., «Obras de la escuela quiteña en Extremadura», Quiroga, $\mathrm{n}^{\circ}$ 12, julio-diciembre, 2017, pp. 27-130; «Efigies del poder en el siglo XIX. Las galerías de retratos de gobernantes de México y su proyección en las artes plásticas: de Hernán Cortés a Benito Juárez», en Coloquio Internacional Artes plásticas y cultura visual del siglo XIX en México. Conexiones entre España y América, Puebla, BUAP, Colección Lafuente, 2019; PIZARRO GÓMEZ, F.J. y DÍAZ MAYORDOMO, A., «Arquitectura, artificio y memoria simbólica: la consagración del nuevo convento de San Francisco en Lima (1673) y el obispo Mollinedo», en Barroco de Ambos Mundos. Miradas desde Puebla, Nueva York, IDEA/IGAS, 2019, pp. 245-261. 
En la temática de nuestra propuesta, relacionada con el estudio y las conexiones del patrimonio cultural iberoamericano en las diferentes ramas artísticas y humanísticas, son pocos los avances en las Tecnologías de la Información y la Comunicación, lo cual denota una importante oportunidad dentro del espacio científico, así como su transformación y pertinencia en la sociedad. Por este motivo nace el proyecto, «Monumenta Iconográfica Americana: la imagen de América en las artes europeas e iberoamericanas» (MOICAM), ideado con una perspectiva de estudio acerca de la iconografía de la imagen del continente en los tiempos de la modernidad y la contemporaneidad en el espacio iberoamericano.

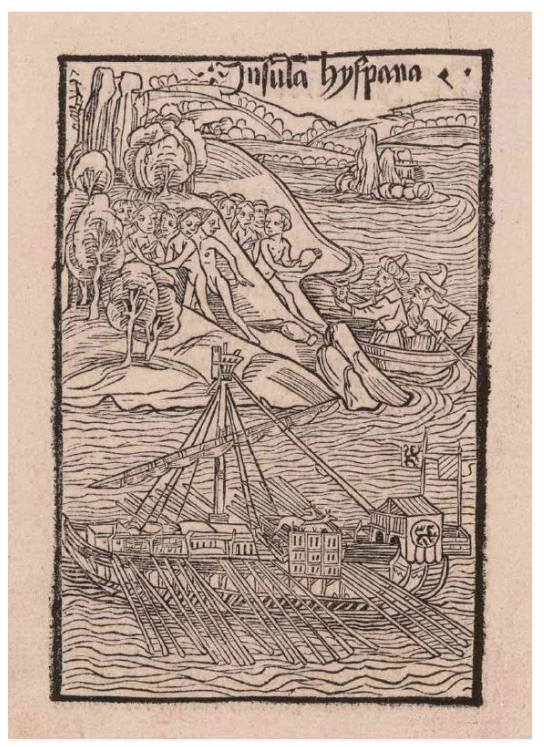

Figura 1.- "Insula Hyspana", Cartas que anunciaron el descubrimiento de las Indias, Basilea, 1493. Biblioteca John Carter Brown de Estados Unidos de América.

Figura 2.- Josep Lluís Pellicer, Gloriosa tornada dels ossos de Colón á Espanya, en La Campana de Gràcia, nº 1537 (29-10-1898).

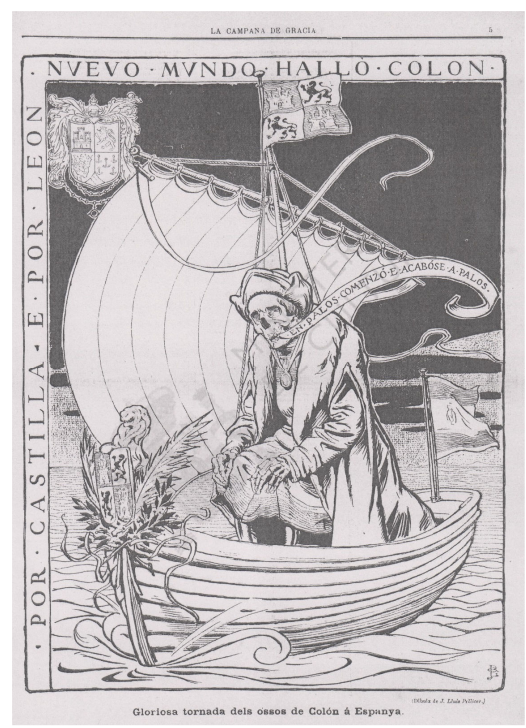


Este repertorio iconográfico americanista pretende ofrecer un recorrido visual, desde las cartas ilustradas de Colón impresas en 1493 (Figura 1) hasta la propia imagen del continente americano en el panorama cinematográfico, así como en otros medios tradicionales de comunicación del siglo XX (libros, revistas, etcétera) (Figura 2), haciendo especial hincapié en la imagen de la mujer, de forma transversal en cada una de las secciones del proyecto, y de forma monográfica en una de las partes fundamentales del mismo. En este sentido, es necesario tener en cuenta que la iconografía relacionada con el continente americano habitualmente aparece representada como una alegoría femenina con una serie de atributos que, como metáforas ilustradas, se utilizan para hacer perceptible a la vista el concepto que se pretende alegorizar. Para esta representación serán necesarias las noticias de los cronistas de Indias, influidos a veces por las leyendas que suscitó el descubrimiento del Nuevo Mundo. Nacía así una nueva imagen iconográfica y simbólica que cambiaría según las épocas, los países y las modas, y que encontraremos en diferentes repertorios, libros, revistas o tratados iconográficos. Una de las primeras representaciones simbólicas del continente americano aparece en la obra de Abraham Ortelius, Theatrum Orbis Terrarum, publicado en 1570, o en la Iconología de Cesare Ripa (1603) acompañada de grabados donde representaba las cuatro partes del mundo (Figura 3). Una de las más significativas de este momento quizá sea la del grabador flamenco Theodor Galle, que alrededor de 1580 representaba a América como una mujer desnuda sentada en una hamaca que tendía su mano en señal de petición de aceptación hacia un hombre europeo portador de un estandarte y de un sextante 9 (Figura 4). El fondo escénico estaba dividido entre una parte marítima, donde aparecía una carabela sobre un océano que se extendía hacia el horizonte, y otra terrestre, en la que se distinguían animales exóticos, un paisaje montañoso cubierto por una vegetación exuberante $y$, en un plano más alejado, una escena de canibalismo. Esta representación, eminentemente eurocéntrica, se basaba en una visión tan abstracta como improbable de lo que era la realidad, y fue inspirada por las descripciones deformadas de cronistas como Juan de Grijalva o Bernal Díaz del Castillo. Este grabado de finales del siglo XVI establecería ya unos códigos tradicionales iconográficos de la representación alegórica americana que van a subsistir, en parte, hasta principios del siglo XX y este proyecto intentará mostrar una visión más completa de estas imágenes.

9 Theodoro Galle, Philippe Galle y Jan Collaert after Jan Van Der Straet, Amerigo Vespucci rediscovers América, from novo reperta, 1580. Foto: Bridgeman Arte Library-Giraudon/Art Resource, New York. 
Figura 3.- Cesare Ripa, Alegoría de América, Iconología, 1593.
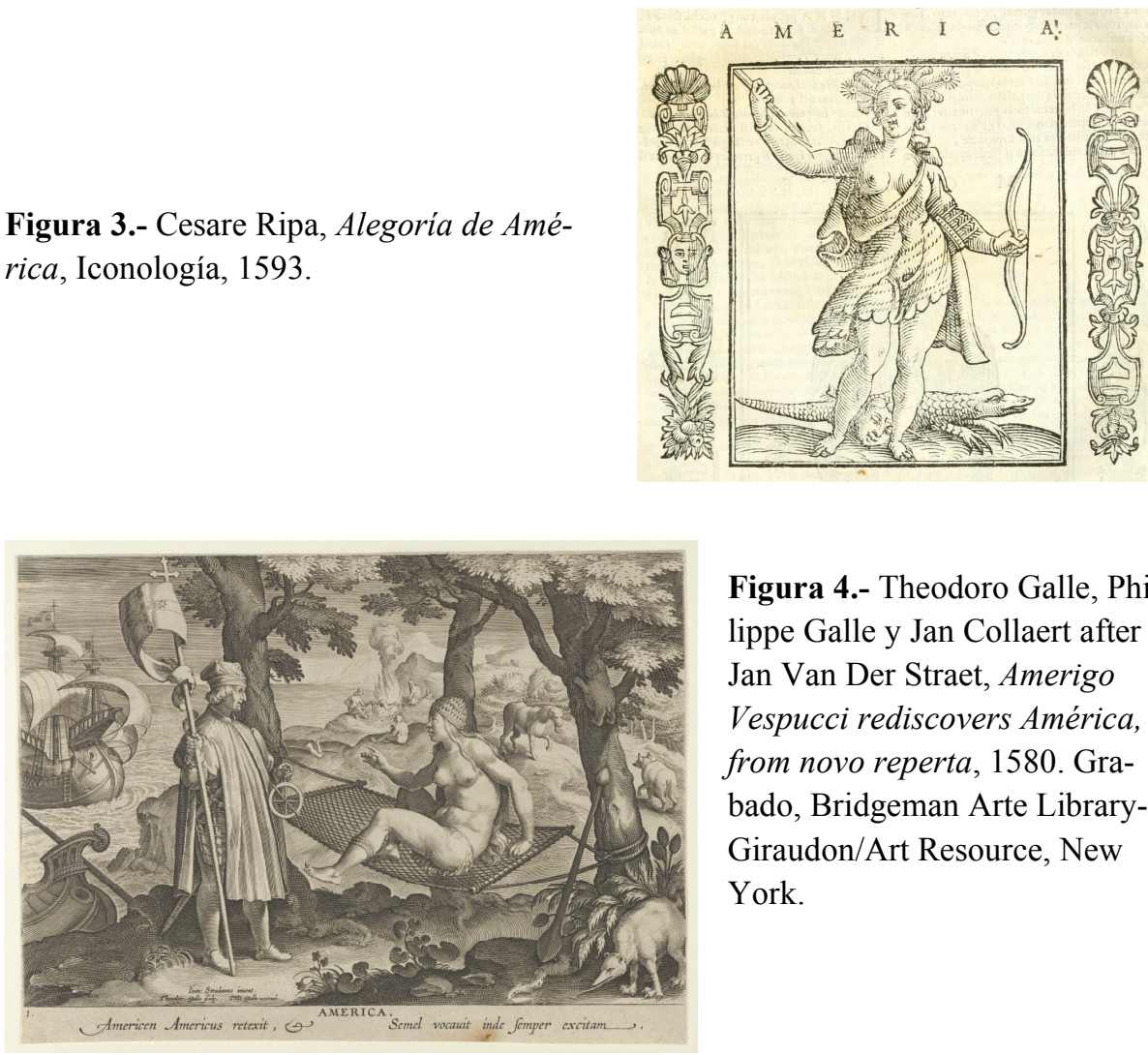

Figura 4.- Theodoro Galle, Philippe Galle y Jan Collaert after Jan Van Der Straet, Amerigo Vespucci rediscovers América, from novo reperta, 1580 . Grabado, Bridgeman Arte LibraryGiraudon/Art Resource, New York.

Precisamente, uno de los objetivos que se pretende con el proyecto MOICAM es realizar un trabajo de búsqueda y recopilación de imágenes en archivos, museos, centros de investigación, bibliotecas y fondos documentales y bibliográficos, para crear un banco de imágenes con las siguientes secciones generales ${ }^{10}$ :

- La iconografía del descubrimiento y la imagen de la ocupación del territorio. (Figura 5)

- La formación de la imagen alegórica de América.

- La visión del Nuevo Mundo en el grabado y la cartografía.

- La imagen de la mujer en el imaginario americanista.

10 FERNÁNDEZ MUÑOZ, Y., La imagen de América. Disponible en: https://acortesg01.wixsite. com/laimagendeamerica/gallery 
- La imagen de América en los tratados europeos de iconografía e iconología.

- Los protagonistas del descubrimiento y la conquista. La formación de su imagen plástica.

- Imágenes fantásticas sobre América. Las creaciones míticas y teratológicas.

- América y el indio en las artes plásticas europeas e iberoamericanas de los siglos XVI al XIX.

- La imagen científica y erudita de América. Desde el Romanticismo hasta nuestros días.

- La imagen de América en el mundo contemporáneo y sus medios de comunicación.

- La imagen y los ecos de América en Extremadura.

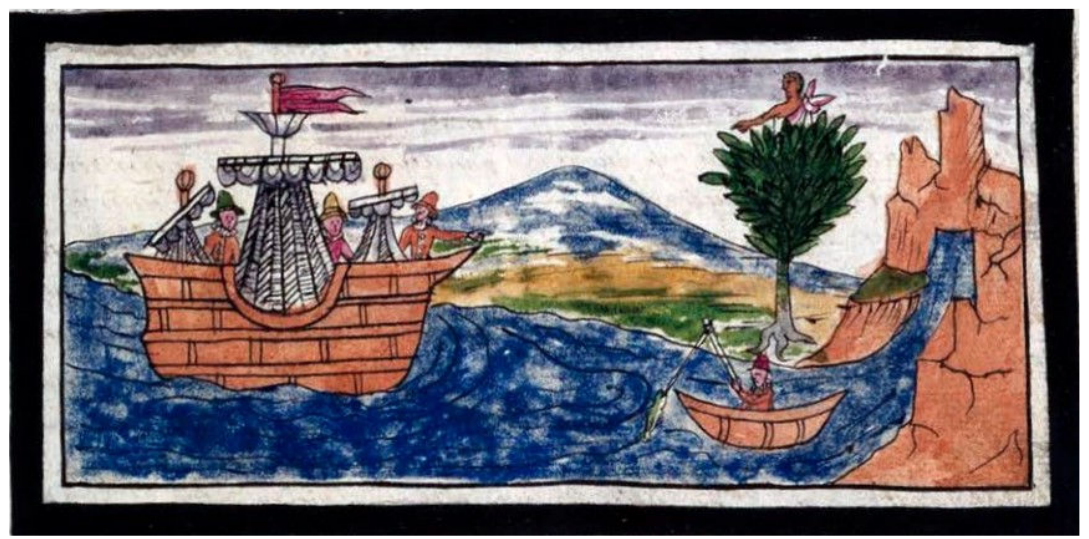

Figura 5.- Fraile dominico Diego Durán, Códice Durán o Historia de las Indias de Nueva España e Islas de Tierra Firme., segunda mitad del siglo XVI.

De esta manera, la configuración de estos campos prioritarios está permitiendo la recopilación de grabados, dibujos, pinturas, esculturas, fotografías, mapas, etcétera., donde la dimensión iberoamericana es el tema fundamental o complementario en los aspectos anteriormente mencionados. Consecuentemente, este catálogo iconográfico va a posibilitar un esbozo analítico de la evolución de la imagen de América a lo largo de sucesivas etapas o acontecimientos históricos, y de las diferentes manifestaciones artísticas, permitiendo así una comparativa del contenido visual que la historia, la literatura o el cine nos ha ofrecido de la imagen de América a lo largo de siglos. Compendiar el conjunto de imágenes que 
se ha dado por colonizadores, exploradores, artistas, viajeros, expedicionarios, cartógrafos, cineastas, publicistas, etcétera, permitirá disponer de una visión completa y sin filtros mediáticos de los diferentes relatos que sobre el continente americano se ha dado a lo largo de la historia, incluso hasta nuestros días. (Figura 6). A su vez, la confrontación entre el discurso eurocéntrico y masculino que ha protagonizado históricamente la imagen del Nuevo Mundo, frente al americanista y femenino, entendemos que debe ser uno de los resultados científicos y sociales del proyecto. Asimismo, no se trata de un banco de imágenes cerrado, sino que será posible la incorporación de nuevas imágenes y recursos tras la finalización del proyecto, facultando la inclusión de contenido novedoso previa adopción de los filtros necesarios para garantizar la fiabilidad y la veracidad.

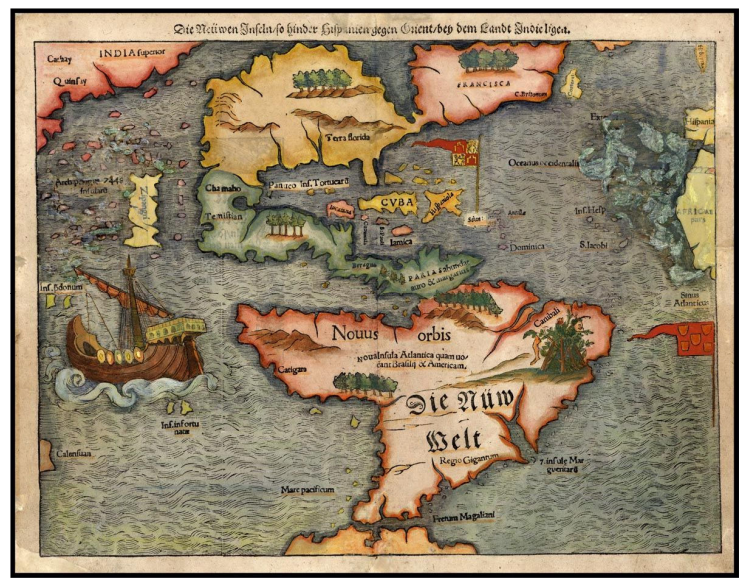

Figura 6.- Sebastián Munster, Mapa de América, 1561.

\section{ORIGEN Y PLANTEAMIENTO DEL PROYECTO}

La imagen de América, en sus diferentes expresiones y manifestaciones, ha sido uno de los temas más fecundos que ha producido la iconografía de los cinco continentes. Ningún otro como el americano ha sido objeto de tantas formas representativas y motivo de disputas y controversias, derivadas en ocasiones de su utilización como arma política e ideológica desde sus orígenes hasta los tiempos de la contemporaneidad histórica.

El análisis de la imagen de América en los diferentes aspectos y manifestaciones ha sido causa de estudio y reflexión por parte de historiadores e historiadores del arte desde las primeras décadas del siglo XX, destacando en este sentido los trabajos pioneros de J.H. Hyde, «L'iconographie des Quatre Parties du Monde dans les tapisseries» (Gazette des Beaux-Arts, 10, 1924) y «The four 
parts of the world as represented in old-time pageants and ballets» (Apollo, 1926, II y 1927, I). Pero sería a partir de los años setenta del siglo pasado cuando la imagen de América comienza verdaderamente a interesar a los investigadores de uno y otro lado del Atlántico. Este es el caso R. E. Alegría, Las primeras manifestaciones del indio americano, 1493-1523, Puerto Rico, 1978; F. Chiapelli (ed.), First Images of America, Berkeley, 1976; H. Honour, The European vision of America, Cleveland, 1975, y sobre todo The New Golden Land: Europen Images of America fron the Discoveries to the Present Time, New York, 1975, aunque algunos años antes Francis Spar había publicado un trabajo que abrió nuevos horizontes en esta línea de investigación («L'Amérique en images», Connaissance des Arts, 112, 1961).

No obstante, sería en la década de los ochenta y noventa del siglo pasado cuando el interés por el tema de la imagen del continente americano aumente de manera considerable, siendo objeto de monografías, artículos, ponencias en congresos, etcétera. Es necesario tener en cuenta la importancia que en este terreno supuso la obra de O'Gorman, La invención de América (1958), que abrió el camino para el desarrollo de estudios teóricos sobre cómo desde 1492 se produjo la creación de una imagen del Nuevo Mundo a imagen y semejanza del Viejo Continente. Por otra parte, en 1997 se edita la monumental y enciclopédica obra América de T. de Bry por Ediciones Siruela, que marcará un antes y un después en el estudio de la iconografía americanista. Este es el momento en el que los historiadores del arte de España comienzan a ocuparse de este tema, dando lugar a algunos de los trabajos sobre cuya metodología se fundamenta este proyecto. Nos referimos a estudios como los de E. Amodio, Formas de alteridad. Construcción y difusión de la imagen del indio americano en la Europa durante el primer siglo de la conquista de América (1993); C. García Saiz, «La imagen del indio en el arte español del Siglo de Oro», en La Imagen del indio en la Europa moderna (1990); S. Sebastián López, Iconografía del indio americano (1992) o M. Rojas Mix, América imaginaria (1992), entre otros ${ }^{11}$. Más recientemente se han publicado otros trabajos, aunque no es un

11 BUCHER, B., Icon and Conquest: A structural Analysis of the illustrations of the Bry's Great Voyages, Chicago, 1981; DUVIOLS, J.P., L'Amerique espagnole vue el rêvée. Les livres de voyages de Christophe Colomb à Bougainville, París, 1975; ELLIOTT, J. H., «De Bry y la imagen europea de América», en América (1590-1634), Siruela. Madrid, 1997; GARCÍA ARRANZ, J.J. «Monstruos y mitos clásicos en las primeras crónicas e imágenes europeas de América: los acéfalos», en Humanismo y pervivencia del mundo clásico: homenaje al profesor Luis Gil, Alcañiz, 1997, pp. 337-348; GARCÍA SAIZ, C., «América en el arte español del siglo XVIII: Tradición y cambio», Cuadernos de Arte Colonial, $\mathrm{n}^{\circ}$ 5, Madrid, 1989; GIL, J., Mitos y utopías del Descubrimiento, Madrid, Alianza Universal, 1989; GISBERT, T., Iconografia y mitos indígenas en el arte, La Paz, 1980; MORALES Y MARÍN, J.L., La iconografía del descubrimiento de América, Valencia, 1992; PÉREZ, J. (ed.), La imagen del indio en la Europa moderna, Sevilla, Escuela de Estudios Hispano Americanos de Sevilla/C.S.I.C., 1990; ROZAT, G., Indios 
tema que haya sido frecuentado por los investigadores, razón por la cual el objetivo de este proyecto se hace más pertinente y necesario ${ }^{12}$.

Por tanto, entre los objetivos de este proyecto se encuentra fundamentalmente, crear una base de datos de la imagen de América en todas sus variantes iconográficas, de carácter enciclopédico y no cerrada, a partir de la documentación recabada en las distintas instituciones científicas, académicas y cultura1 es ${ }^{13}$, y de los resultados obtenidos tras el análisis de la documentación de los mismos en función de los criterios tipológicos e iconográficos ${ }^{14}$ (Figura 7). Además, se busca la participación activa, por parte de los investigadores y posibles colaboradores para que se involucren en el proyecto, para ir incrementado y completando el número de imágenes de la base de datos. Para el desarrollo de este proceso se han fijado las bases, criterios y procedimiento de evaluación con el fin de garantizar que las nuevas incorporaciones dispongan de los requisitos necesarios de veracidad y fiabilidad. Esta herramienta informática permite,

imaginarios, indios reales, México, Editorial Tava, 1992; VV.AA. New World of Wonders. European Images of the Americas, 1492-1700, Washington, 1992; RAMÍREZ ALVARADO, M.M., «Mitos e información: geografía fantástica y primeras apreciaciones del continente americano», Revista Latina de Comunicación Social, La Laguna, 1998, pp. 1-12.

12 BUSTAMANTE, J., «La invención del indio americano y su imagen: cuatro arquetipos entre la percepción y la acción política», Revista Nuevo Mundo Mundos Nuevos, 2007; CARREÑ, G., «El pecado de ser otro, análisis de algunas representaciones monstruosas del indígena americano», Revista Chilena de Antropología Visual, n¹2, Santiago de Chile, diciembre 2008, pp. 127-146; CUENCA RUIZ, E. y DEL OLMO RUIZ, M., América. Iconografia del descubrimiento, Guadalajara, Jesús E. Padín-Intermedio Ediciones, 2013; EGAÑA, D., «Lo monstruoso y el cuerpo fragmentado: el Nuevo Mundo como espacio de violencia, una lectura de la obra de Theodore De Bry en la construcción de la imagen indiana», Revista Chilena de Antropología Visual, n¹6, diciembre 2010, pp. 1-29; GRUZINSKI, S., La guerra de las imágenes: de Cristóbal Colón a Blade Runner. 1492 a 2019, México, Fondo de Cultura Económica, 2006; GUTIÉRREZ, R. y GUTIÉRREZ VIÑUALES, R., «Construcciones iconográficas de las naciones americanas y España», en América y España, imágenes para una historia. Independencias e identidad 1805-1925, Madrid, Fundación MAPFRE 2006, pp. 8-46; LIRA, M., «La representación del indio en la cartografía de América», Revista Chilena de Antropología Visual, 2004, pp. 86-102; MAGASICH, J. y DE BEER, J.M., América mágica. Mitos y creencias en tiempos del descubrimiento de América, Santiago de Chile, Editorial LOM, 2001; NIETO ORRIOLS, D., «La tradición clásica en las imágenes de América: pervivencia de los modelos y tópicos grecolatinos en la Conquista», Historias del Orbis Terrarum, $\mathrm{n}^{\circ} 8$, Santiago de Chile, 2011, pp. 87-105; PINYOL VIDAL, J., «Imágenes y estereotipos iconográficos de América en las ilustraciones de la prensa peninsular de finales del siglo XIX», Amerika, vol. XIV, 2016; RAMIREZ ALVARADO, M. del M., «Images for the History of Communication: The First Engravings from the Americas. Advances in Historical Studies», Scientific Research Publishing, 2015, vol. IV, $\mathrm{n}^{\circ} 1$, pp. 51-64; SÁENZ-LÓPEZ, S., «Las primeras imágenes occidentales de los indígenas americanos: entre la tradición medieval y los inicios de la antropología moderna», Anales de Historia del Arte, Madrid, Universidad Complutense, 2011, pp. 463-481; SANFUENTES, O., Desvelando el Nuevo Mundo. Imágenes de un proceso, Santiago de Chile, Universidad Católica de Chile, 2008.

13 FERNÁNDEZ MUÑ̃Z, Y., La imagen de América. Disponible en:

https://acortesg01.wixsite.com/laimagendeamerica/recursos

14 En este sentido será de gran ayuda la experiencia de bancos de imágenes ya existentes, como es el caso de PESSCA (Project on the Engraved Sources of Spanish Colonial Art) y de su responsable Almerindo E. Ojeda. Disponible en: https://colonialart.org/ 
además de almacenar toda la documentación en un único soporte, cruzar información que puede proporcionar nuevas lecturas culturales.

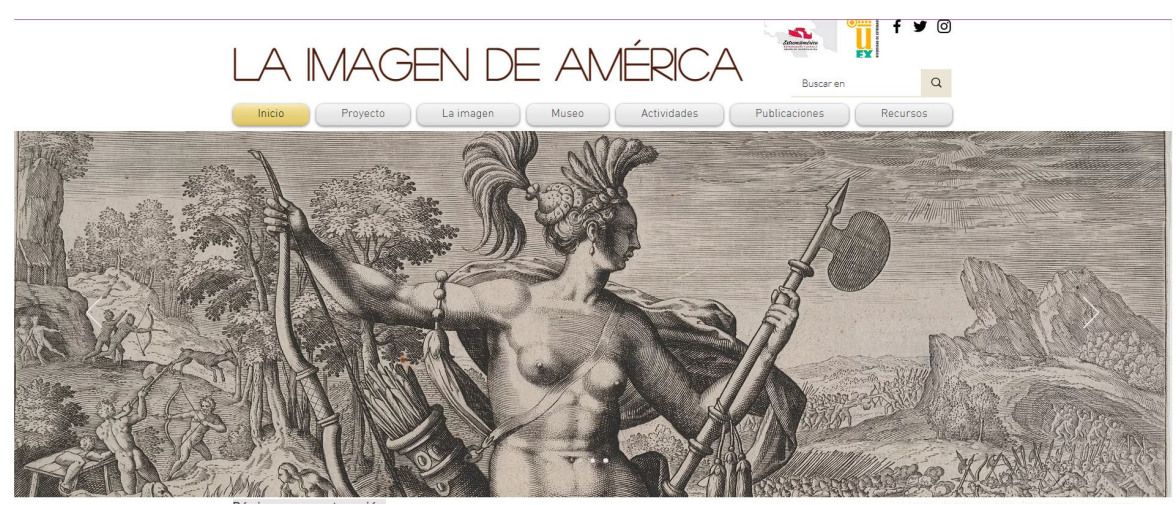

Figura 7.- Fernández Muñoz, Y., La imagen de América, página en construcción del proyecto.

Otro de los objetivos fundamentales de este proyecto es analizar la imagen de la mujer en la iconografía americanista entre los siglos XV y XX. Pues si la iconografía de la mujer en el arte de la Edad Moderna aún está en gran medida por definir, todavía resultan más escasos los estudios centrados en la imagen artística de la mujer americana. Hay que tener en cuenta que la imagen propia y real de América, de sus hombres y de sus mujeres, pasó en gran medida inadvertida a los ojos europeos. La imagen de América y de los pueblos prehispánicos fue inventada por los descubridores que pretendieron «ver» a toda costa la imagen preconcebida que ellos tenían de las Indias Occidentales. Las falsificaciones iconográficas transformaron la realidad y exportaron al viejo continente un repertorio visual irreal sólo superado en el siglo XVIII. Asimismo, las imágenes de la sociedad virreinal fueron escasas, y tamizadas igualmente por el prisma europeo, y únicamente bajo la Ilustración empezamos a descubrir el entramado étnico y social de la América colonial. En este contexto de imágenes camufladas o robadas, la imagen de la mujer americana resulta aún más difícil de descubrir ${ }^{15}$, de ahí que se presente como uno de nuestros objetivos fundamentales, pues no ha sido analizado desde una perspectiva de género.

También se pretenden analizar los ecos americanistas en el patrimonio extremeño, desde la representación plástica de extremeños que tuvieron un

15 MÍNGUEZ CORNELLES, V., «La imagen de la mujer americana en el arte y en la emblemática novohispana: los espejos regios», Asparkía, nº 5, 1995, pp.25-36. 
destacado papel en el proceso de descubrimiento, dominio y organización del territorio iberoamericano, así como de esos otros extremeños y extremeñas que sin gestas, crónicas ni biografías que les recuerden, realizaron una ingente labor de evangelización, administración, aculturación y mestizaje, contribuyendo en gran medida a conformar ese fenómeno globalizador que fue y es lo iberoamericano, así como las muestras artísticas del patrimonio extremeño en las que se hace patente la presencia de extremeños en América, como es el caso especial del Cristo de la Encina o de la Virgen de Guadalupe de México.

Como la proyección de los recursos digitales es uno de los objetivos fundamentales de este proyecto, asimismo se pretende crear un Museo Iberoamericano Virtual a partir de los resultados obtenidos, con una exposición permanente mediante la selección de aquellas imágenes que mejor ilustren las diferentes «salas», las cuales se planificarán museográficamente en función de los principales apartados en los que se agrupen las imágenes en la base de datos. Además, se plantea la posibilidad de realizar exposiciones temporales, como «América en Extremadura» ${ }^{16}$, que podría utilizarse como una de vía de difusión del patrimonio extremeño, donde se reflejaran los siglos de contacto con el continente americano para mostrar no solo la influencia de lo español/extremeño en América, sino también para destacar lo que el Nuevo Continente proporcionó cultural e históricamente a Extremadura (Figura 8).

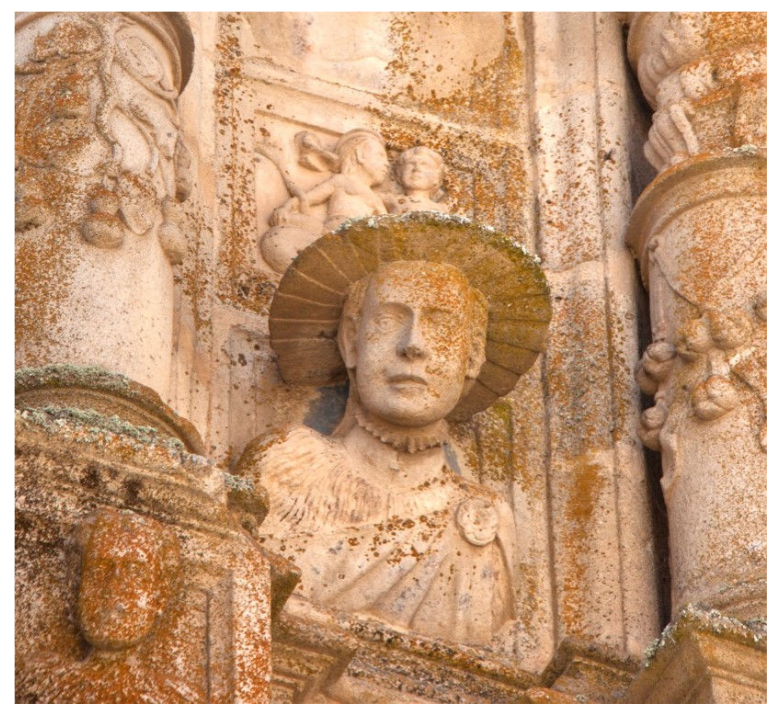

Figura 8.- Francisca Pizarro Yupanqui, hija de Francisco Pizarro. Detalle del balcón de esquina del Palacio de la Conquista de Truji1lo, Extremadura. Foto: Fernández Muñoz, Y.

16 En la actualidad no existe un museo virtual dedicado a la imagen de América en el que se exponga la iconografía que el continente americano ha generado a lo largo de los siglos. 


\section{ORIGINALIDAD Y PERTINENCIA DE LA PROPUESTA}

El estudio de la imagen de América se introduce en la cultura simbólica europea a finales de los ochenta, pero es evidente que la imagen contemporánea de América está muy mediatizada y polarizada entre los defensores de la presencia europea en el Nuevo Mundo y los críticos sobre estos mismos acontecimientos históricos. Esto se ha visto reflejado en el resultado de encuestas y proyectos de investigación de la imagen de América Latina entre la población joven española. Este es el caso, por ejemplo, del trabajo de Pedro Pérez Herrero y María Jesús García-Arévalo Calero, «La imagen de América Latina entre la población estudiantil española» (13-18 años $)^{17}$. También es singular el trabajo de la Dra. Campos Pérez, «La imagen del indio en la construcción históricocultural de la identidad. Estudio comparado de su representación iconográfica en los manuales escolares de México y España (1940-1945)» ${ }^{18}$. Entre las conclusiones a las que se llegó en este estudio, de donde radica la novedad del presente proyecto, se expresaba lo siguiente:

«En síntesis, hay que subrayar que, al haberse demostrado la importancia de cada una de las variables manejadas en la conformación de imágenes, así como el complejo entrecruzamiento de sus efectos, se comprueba que el contenido de los libros de texto no debería ser programado como si la actividad escolar curricular fuera el único o más importante mecanismo conformador de la imagen de América Latina. En consecuencia, si una de las líneas de las políticas educativas se propone adecuar las imágenes que la sociedad española maneja de América Latina con la misma de aquel continente y de sus habitantes a fin de evitar tanto los estereotipos paternalistas-benignos como los negativos emanados de actitudes de sentimientos de superioridad, se tendrá que contar, aparte de los libros de texto, con los contenidos de las actividades extracurriculares por lo que parece necesario establecer algún marco general de referencia-, $\mathrm{y}$ tener en cuenta los efectos que puedan estar produciendo al mismo tiempo y de forma paralela los medios de comunicación o relaciones (familia, amigos, compañeros, vecinos, viajes, cartas) de los estudiantes con los latinoamericanos».

La imagen es, de alguna manera, un relato que, en función de las circunstancias históricas de cada momento, se ha manipulado y mediatizado por el discurso oficial dominante. Por todo ello, es evidente compendiar el conjunto de imágenes sobre el territorio americano, generando un relato real y auténtico, sin ideologías ni distorsiones, que emane de los trabajos de recopilación y

17 Revista Iberoamericana de Educación, Número 6, 'Género y Educación', septiembre-diciembre 1994. Disponible en: https://rieoei.org/historico/oeivirt/rie06a06.htm.

18 En Memoria y Sociedad, vol. 14, n² 28, enero-junio 2010, pp. 107-124. 
análisis del material documental. Consecuentemente, la originalidad de este proyecto, aparte de cubrir las lagunas existentes en el campo de la investigación científica sobre la imagen de América en el territorio iberoamericano, pone el foco de atención hacia la creación y logro de la citada base enciclopédica iconográfica (desde el s. XV al XX) en todas sus variantes, temáticas, formatos y géneros, debidamente organizada y sistematizada. Como valor adicional, la colección de las imágenes de la mujer puede suponer un gran aliciente para los estudios de género, sirviendo de apoyo gráfico a los análisis históricos, culturales, sociales, sociológicos, etcétera, sobre el papel de la mujer en el fenómeno americanista y en la imagen actual de la mujer latinoamericana, tanto en Europa como en Iberoamérica. Sirva como ejemplo de ello y de lo que pretendemos llevar a cabo en este proyecto, la imagen que las Galerías Lafayette de París utilizaron en 1973 en una semana de ventas especial dedicada a América Latina. En los carteles que anunciaban esta semana el motivo principal era el de una mujer al modo de guerrillera y aspecto fiero. De este modo, con este proyecto pretendemos buscar las raíces de esta imagen de América Latina y la mujer, indagando en el imaginario colectivo que se construye a lo largo de siglos de imágenes que tenían una evidente e ideológica intencionalidad.

Por otro lado, la innovación viene dada con el diseño y creación del Museo Iberoamericano Virtual y su internacionalización, motivado por su carácter digital y el acceso libre a los investigadores y la sociedad en general. Esto permitirá ahondar en ideas y razonamientos susceptibles en diseñadores, periodistas, productores de documentales, dibujantes de comics o videojuegos, diseñadores de moda..., al ser esbozado mediante una lógica gráfica y visual.

En el caso de Extremadura, se está compendiando y analizando todas aquellas imágenes de extremeños que tuvieron un destacado papel en el proceso de descubrimiento, dominio y organización del territorio iberoamericano, como los Pizarro, Cortés, Balboa o Valdivia, pero también de esos otros extremeños y extremeñas que, sin gestas, crónicas, ni biografías que les recuerden, realizaron una ingente labor de evangelización, administración, aculturación y mestizaje, como es el caso del cartógrafo Alonso de Pineda o el arquitecto trujillano Francisco Becerra, entre otros. También se están catalogando todas aquellas obras que representan la imagen de América en Extremadura a través de sus protagonistas, contribuyendo en gran medida a conformar ese fenómeno globalizador que fue y es lo iberoamericano. Además, añadimos otro enfoque práctico procedente de la elaboración de contenidos extracurriculares que vendrán a servir de apoyo a centros de enseñanza secundaria de la región extremeña, permitiendo así la exposición de los resultados del proyecto. Todo ello, sin perder de vista el matiz social y de colaboración con los gobiernos en aquellas 
localidades donde prevalecen las resonancias americanistas en el arte y el patrimonio cultural extremeño, aportando una visión más razonada sobre los sucesos históricos y aspectos artísticos-culturales de nuestra región (Figura 9).

Figura 9.- Nicolás Eustache Maurín, El jefe Zingari presenta a Aida, su hermana, a Cortés, Litografía, s. XIX, Museo de América, España.

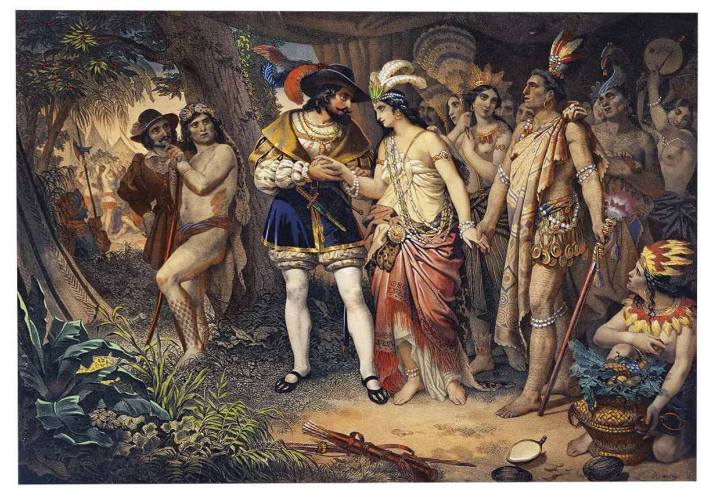

Más allá del acercamiento con lo local, desde el ámbito académico pretendemos propiciar sinergias y colaboraciones de la Universidad de Extremadura con Institutos y Centros de Investigación de carácter internacional, destacando el Instituto Warburg de Londres, el Centro de Documentación de Arte y Arquitectura Latinoamericanas (CEDODAL) de Argentina, el Instituto Indigenista Internacional y el Instituto Nacional de Antropología e Historia de México, favoreciendo un vínculo de unión en la transferencia del conocimiento y, en consecuencia, la posibilidad de idear y trazar futuros estudios, publicaciones o eventos científicos promovidos por el grupo de investigación Extrem@mérica.

En definitiva, la imagen es, de alguna manera, un relato que, en función de las circunstancias históricas de cada momento, se ha manipulado y mediatizado por el discurso oficial dominante, de forma que la proyección de unas imágenes frente a otras contribuyó a la construcción de dicho relato, lo que ha llegado hasta nuestros días en forma de concepciones ideologizadas y distorsionadas de la realidad histórica y de la realidad actual del continente. El banco de imágenes resultante del proyecto permitirá a los investigadores de diferentes áreas de conocimiento apuntalar sus hipótesis y conclusiones de manera gráfica, bien para avalar las mismas o, por el contrario, para poner de manifiesto que las imágenes se instalan en un discurso contrario a la realidad y veracidad histórica. 


\section{LA DIFUSIÓN DEL PROYECTO}

Precisamente, aunque por la propia naturaleza del proyecto, su proyección en la red ya constituye un importante modo de difusión y de sus resultados, es evidente la necesidad de llevar a cabo un plan de difusión del mismo. Con este horizonte, se plantean algunas iniciativas, como la elaboración de un documento informativo sobre el contenido de la base de datos para difundirlo en instituciones científicas, culturales, sociales, etcétera o un programa de charlas divulgativas sobre la base de datos en centros educativos, científicos, sociales, económicos y culturales o crear perfiles en las redes sociales (Facebook, Instagram, Twitter) con el fin de ir actualizando las posibles novedades y actividades desarrolladas.

La base de datos resultante del proyecto de investigación arrojará un corpus gráfico susceptible de ser utilizado para diferentes campos académicos y productivos, facilitando, mediante el tesaurus de términos, una búsqueda fácil y sencilla. También puede ser utilizado para la producción y diseño de indumentarias, escenarios, etcétera en el teatro, el cine, la televisión y los videojuegos, o la producción de libros y materiales didácticos para la enseñanza media y superior.

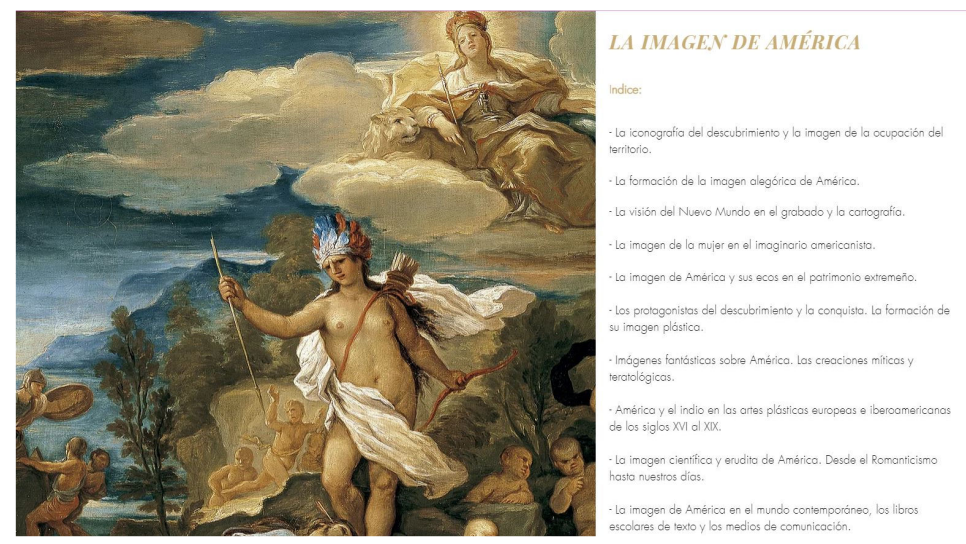

Figura 10.- Proyecto del libro, La imagen de América, realizado por el grupo de investigación Extrem@mérica en proceso de edición.

Por otro lado, pretendemos propiciar publicaciones, comunicaciones, ponencias, paneles..., que recojan los resultados de la investigación a partir de la compilación de imágenes, con la idea de editar un libro titulado La imagen de América, donde cada capítulo aborde una de las diez líneas temáticas 
propuestas inicialmente en el proyecto. Además, creemos que la edición de una revista digital anual a través de la plataforma virtual del proyecto, puede dar a conocer todas las investigaciones y novedades del mismo, tal como recogemos en la base de datos en construcción realizada por el grupo ${ }^{19}$ (Figura 10). Finalmente, creemos que la organización de varias jornadas sobre «La imagen de la mujer en la iconografía americanista»o «La imagen de América en el patrimonio extremeño», permitirán dar a conocer los avances de este proyecto.

\section{BIBLIOGRAFÍA}

ALEGRÍA, R. E., Las primeras representaciones gráficas del indio americano, 1493-1523, Puerto Rico, Centro de Estudios Avanzados de Puerto Rico y el Caribe, 1978.

AMODIO, E., Formas de alteridad. Construcción y difusión de la imagen del indio americano en la Europa durante el primer siglo de la conquista de América, Caracas, Editorial Abya Yala, 1993.

BRY, T., América, Madrid, Ediciones Siruela, 1997.

CAMPOS, L., «La imagen del indio en la construcción histórico-cultural de la identidad. Estudio comparado de su representación iconográfica en los manuales escolares de México y España (1940-1945)», Memoria y Sociedad, vol. 14, nº 28, Bogotá, enero-junio 2010, pp. 107-124.

CHIAPELLI, F. (ed.), First Images of America, Berkeley, University of California Press, 1976 (2 vols.).

GARCÍA SAIZ, C., «La imagen del indio en el arte español del Siglo de Oro», en La Imagen del indio en la Europa moderna, Madrid, CSIC, 1990, pp. 417-432.

HYDE, J. H., «Iconographie des Quatre Parties du Monde dans les tapisseries», Gazette des Beaux-Arts, 10, 1924, pp. 254-255.

HONOUR, H., The European visión of America, Cleveland, Cleveland Museum of Art, 1975.

- $\quad$ The New Golden Land: Europen Images of America fron the Discoveries to the Present Time, New York, 1975.

MÍNGUEZ CORNELLES, V., «La imagen de la mujer americana en el arte y en la emblemática novohispana: los espejos regios». Asparkía, nº 5, 1995, pp. 25-36.

$19 \mathrm{https} / /$ acortesg01.wixsite.com/laimagendeamerica/revista 
O'GORMAN, E., La invención de América: Investigación acerca de la estructura histórica del Nuevo Mundo y del sentido de su devenir (1958), México, Fondo de Cultura Económica, 2010.

PÉREZ HERRERO, P. y GARCÍA-ARÉVALO CALERO, M. J., «La imagen de América Latina entre la población estudiantil española (13-18 años)», Revista Iberoamericana de Educación, $\mathrm{n}^{\mathrm{o}}$ 6, 'Género y Educación', septiembre-diciembre 1994. Disponible en.https://rieoei.org/historico/oeivirt/rie06a06.htm [Consulta: 09/11/2020].

PIZARRO GÓMEZ, F.J., «La iconografía del Nuevo Mundo y su repercusión en las artes españolas y portuguesas», en V Simposio Hispano-Portugués de Historia del Arte. Relaciones artísticas entre la Península Ibérica y América, Valladolid, Universidad de Valladolid, 1989, pp. 215-226.

- «La imagen de Las Antillas. Entre el mito y el tópico», Actas del I Congreso Internacional Nueva España y Las Antillas, Castellón, Universidad Jaime I y el CIAL, 1997.

ROJAS MIX, M., América imaginaria, Barcelona, Lumen/Sociedad Estatal Quinto Centenario, 1992.

SEBASTIÁN LÓPEZ, S., Iconografia del indio americano, Madrid, Tuero, 1992.

SPAR, F., «L'Amérique en images», Connaissance des Arts, 112, 1961.

Yolanda Fernández Muñoz

Universidad de Extremadura

Facultad de Filosofía y Letras Dpto. de Arte y Ciencias del Territorio Avda. de la Universidad s/n C.P. 10003, Cáceres https://orcid.org/0000-0002-9830-5683 yolandafm@unex.es

Alicia Díaz Mayordomo

Universidad de Extremadura Facultad de Filosofía y Letras Dpto. de Arte y Ciencias del Territorio Avda. de la Universidad $\mathrm{s} / \mathrm{n}$ C.P. 10003 , Cáceres https://orcid.org/0000-0001-7891-0109 aliciadm@unex.es 
